\title{
Helicobacter-pylori gastritis associated with gastric outlet and biliary obstruction
}

\author{
J effrey Duman ${ }^{1}$, Maxwell Smith ${ }^{2}$, Augustin Attwell ${ }^{1}$ \\ 1. Department of Internal Medicine, Division of Gastroenterology, University of Colorado-Denver, Aurora, Colorado, \\ United States. 2. Department of Pathology, University of Colorado-Denver, Aurora, Colorado, United States.
}

Correspondence: Augustin Attwell. Address: Denver Health Medical Center, 660 Bannock Street, MC 4000, Denver, CO 80204, United States. E-mail: Augustin.Attwell@dhha.org

Received: March 20, 2014

Accepted: May 5, 2014

Online Published: May 14, 2014

DOI : $10.5430 /$ crcp.v1n2p96

URL: http://dx.doi.org/10.5430/crcp.v1n2p96

\section{Abstract}

Background and aims: Helicobacter pylori (HP) causes peptic ulcer disease and occasionally gastric outlet obstruction (GOO) but not biliary obstruction. We describe a case of severe HP gastritis causing both GOO and biliary stricture.

Methods: Clinic notes, imaging, endoscopy and pathology reports, and hospital course were reviewed. Design: Single case report. Setting: Tertiary care, academic medical center. Participant/s: One patient encountered in clinical practice. The hospital course is described retrospectively. Clinic notes; endoscopy, pathology, and operative reports; imaging studies are discussed. Interventions: CT scan, esophagastroduodenoscopy (EGD), endoscopic ultrasound (EUS), and endoscopic retrograde cholangiopancreatography (ERCP). She received conservative medical treatment.

Results: HP gastritis, GOO, and obstructive biliary stricture were diagnosed by EGD and ERCP. Peptic ulcer and malignancy were excluded. Medical therapy was curative and resolution confirmed by repeat EGD/ERCP.

Conclusions: HP can cause both GOO and biliary stricture, for which medical therapy may be curative.

\section{Key words}

Helicobacter pylori, Bile duct, Endoscopic retrograde cholangiopancreatography

\section{Introduction}

Helicobacter pylori (HP) infection is associated with an increased risk of gastritis, peptic ulcer disease, and lymphoma. Known complications of HP include gastric outlet obstruction, hemorrhage, and perforation. However, neither gastric outlet obstruction nor bile duct obstruction from non-ulcerative HP has been reported previously. Herein we describe a case of severe HP gastritis alone causing both gastric and biliary obstruction. The patient was successfully managed with medical and endoscopic therapy and avoided surgery.

\section{Case report}

A 35-year-old female Burmese immigrant presented with epigastric pain, nausea, vomiting, and a 10-pound weight loss over three months. During the last two weeks she also experienced jaundice and dark urine. Her medical and surgical 
history was unremarkable, and she denied NSAIDs, alcohol, or tobacco use. Physical exam revealed a slightly malnourished, jaundiced female in no distress. Her abdominal exam was normal. Abdominal ultrasound showed a diffusely dilated biliary tree and cholecystolithiasis but no mass or choledocholithiasis.

Esophagastroduodenoscopy (EGD) was performed, revealing an inflammatory mass involving the antrum, pylorus, and duodenal bulb (see Figure 1A) and associated gastric outlet obstruction. No ulcer was seen. The gastric outlet was dilated with a $12 \mathrm{~mm}$ balloon, and subsequently the duodenoscope could be advanced through the mass into the duodenum, revealing pancreatic and biliary orifaces within the distal portion of the mass (see Figure 1B). Endoscopic retrograde cholangiopancreatography (ERCP) showed dual strictures of the proximal pancreatic duct and bile duct within the duodenal wall with ductal dilation upstream. No stone was identified. A biliary stent was placed and biopsies were taken from the mass.

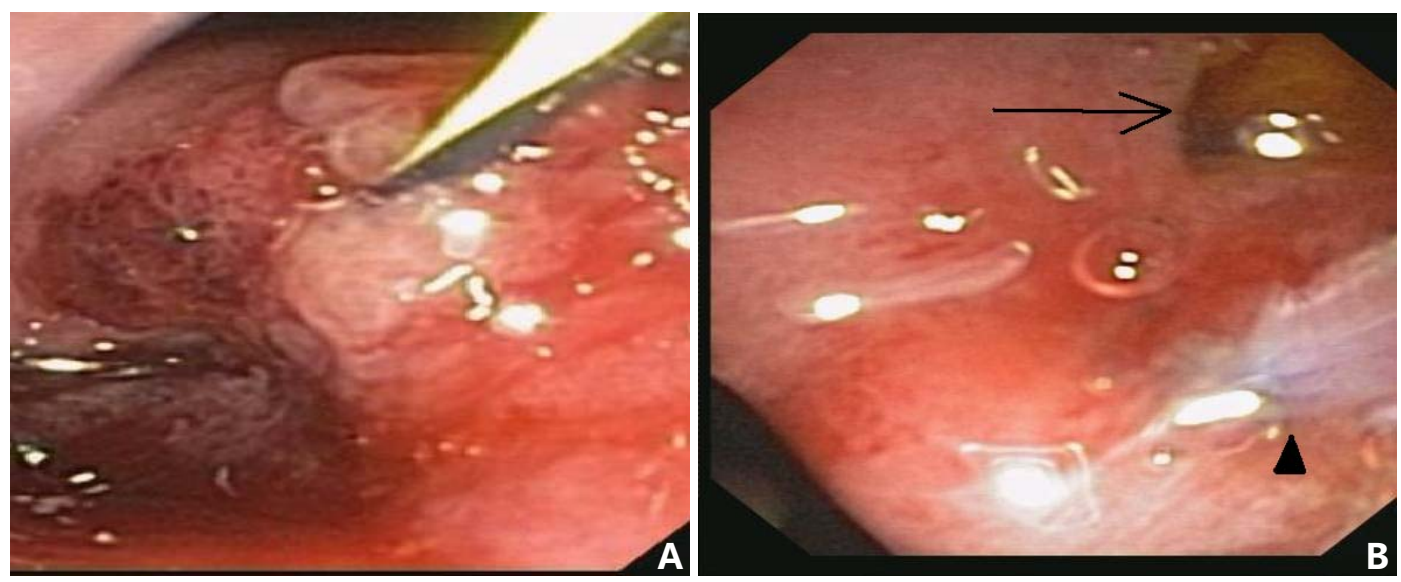

Figure 1. Endoscopic images. A shows an inflammatory mass involving the gastric antrum with a guidewire across the pylorus. B shows the biliary orifice (arrow) and a catheter within the pancreatic orifice (arrowhead) at the distal edge of the mass.
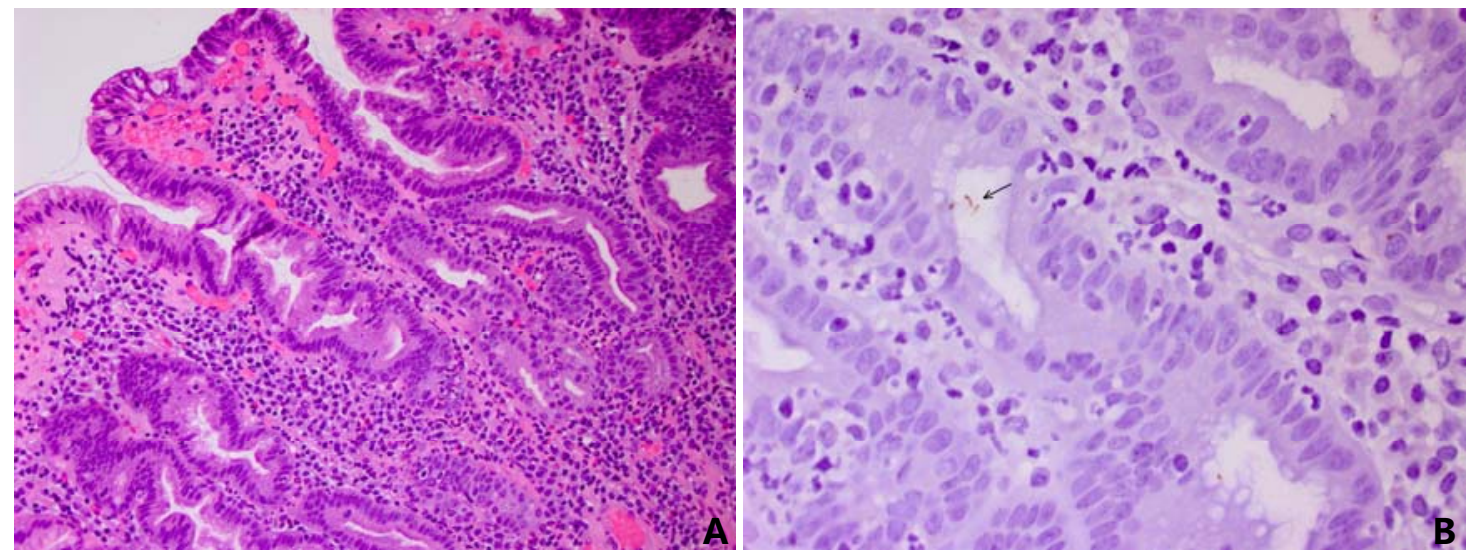

Figure 2. Histology. A shows chronic active gastritis characterized by inflammatory expansion of the lamina propria, intraepithelial neutrophils, and focal intestinal metaplasia on the surface (200×, H\&E). B shows rare, gull-shaped H. pylori organisms within gastric crypts (arrow) (600×, immunohistochemistry for H. pylori).

Histology revealed chronic active HP gastritis and intestinal metaplasia without malignancy (see Figure 2 A-B). Abdominal CT showed marked gastric and duodenal wall thickening and regional lymphadenopathy without additional pathology (see Figure 3). The patient tolerated oral liquids the day after EGD and elected to be discharged rather than undergo further testing. She was treated with liquid-formulation Amoxicillin, Clarithromycin, and Lansoprazole for 2 weeks. 
Figure 3. Contrast abdominal CT scan showing gastric and duodenal wall thickening (black arrow), enlarged regional lymph node (white arrow), and biliary stent (arrowhead).

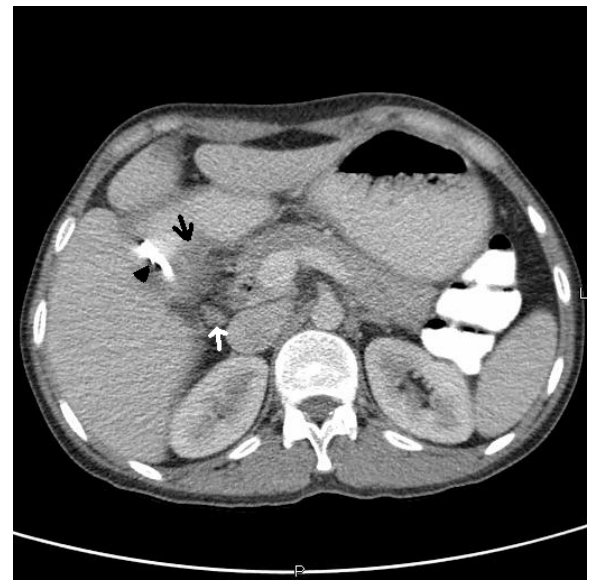

Her symptoms improved, and a repeat EGD one month later showed a focal, benign-appearing pyloric stenosis and a plastic stent protruding from the biliary orifice, which was located in the duodenal bulb (see Figure 4 A-B). Using a gastroscope within the bulb, ERCP showed a diffusely dilated bile duct with a distal "hook-shape" appearance but no stricture. A $10 \mathrm{~mm}$-wide, mobile gallstone was also seen in the proximal common bile duct (see Figure 5). The pylorus was dilated to $15 \mathrm{~mm}$ with a balloon and the biliary orifice was dilated up to $10 \mathrm{~mm}$. The bile duct stone was then extracted without difficulty. No stent was placed. Endoscopic ultrasound (EUS) was also performed, which showed mild, circumferential antral thickening but no mass or enlarged lymph nodes.
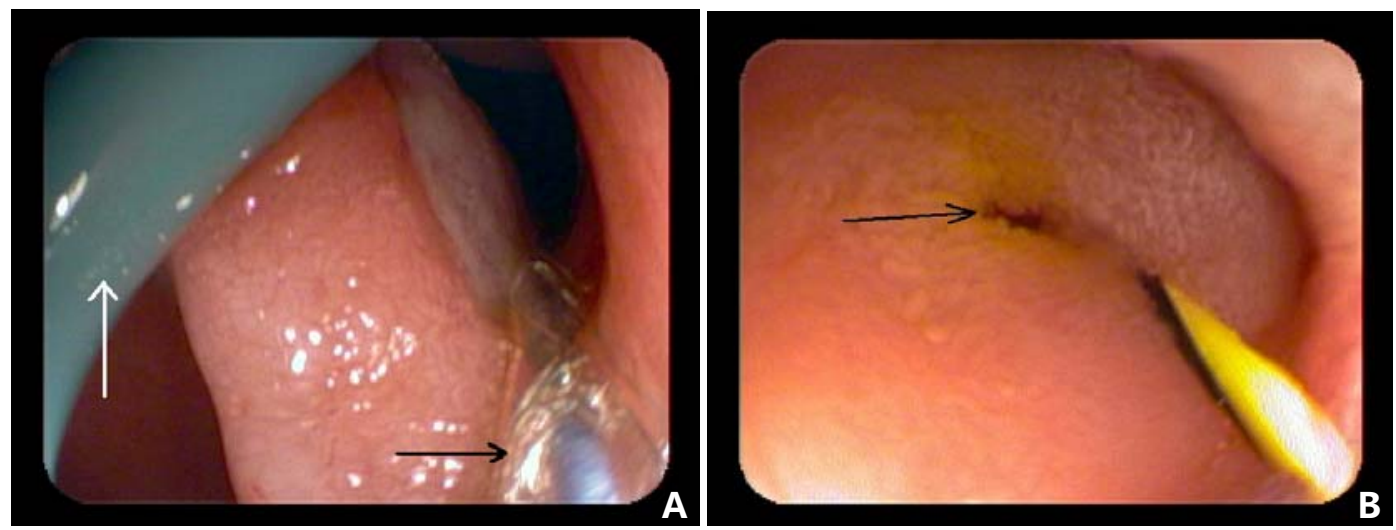

Figure 4. Endoscopic images. A shows mild, benign-appearing pyloric stenosis traversed by a plastic biliary stent (white arrow) and dilating balloon (black arrow). B shows the ectopic biliary orifice located within the duodenal bulb (arrow).

Figure 5. Follow-up ERCP image showing a dilated common bile duct containing a gallstone (arrow).

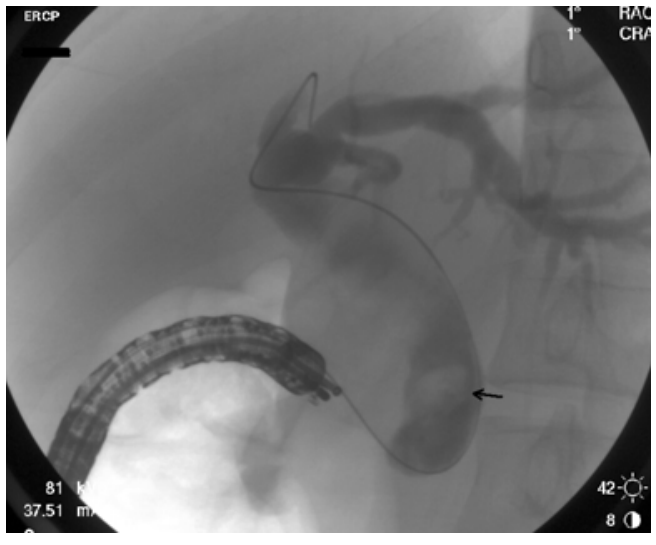

Three months later, the patient was seen in clinic for follow-up. At that time she reported no symptoms and was regaining weight. A stool HP antigen test was negative. She underwent uncomplicated cholecystectomy one month later. 


\section{Discussion}

HP is a spiral-shaped gram-negative rod associated with gastric mucosal infection worldwide. Armed with the virulence factors VacA and CagA, HP causes continuous gastric inflammation in all hosts and may induce a vigorous systemic and mucosal humoral response in some ${ }^{[1]}$. However the clinical course is variable and the majority of infected hosts are asymptomatic. The pattern and severity of symptoms depend on microbial factors and the host's risk factors for complications such as peptic ulcer disease and gastric cancer. Our patient presented with symptoms consistent with a gastric outlet and biliary obstruction and a preliminary diagnosis of malignancy based on EGD and ERCP. However, the subsequent histologic findings and her response to antibiotics confirmed a diagnosis of benign HP gastritis alone.

HP causes peptic ulcers, which can lead to gastric outlet obstruction bleeding, or perforation, but ulcers usually heal without recurrence in response to standard antimicrobial therapy ${ }^{[2-7]}$. An associated obstruction can usually be treated conservatively with balloon dilation, but occasionally surgical resection or bypass is necessary ${ }^{[8]}$. However, no ulcer was seen in our patient and the clinical course and biopsies ruled out cancer. HP gastritis alone, in the absence of an ulcer or malignancy, does not usually create a mass effect or obstruction.

Peptic ulcers obstructing the bile duct are extremely uncommon ${ }^{[9]}$. HP may colonize the biliary tree in up to 53\%-73\% of patients with chronic liver or gallbladder disease ${ }^{[10,11]}$, but the role of HP in biliary disorders is still uncertain. Although HP has been implicated as a possible etiologic factor in primary sclerosing cholangitis or primary biliary cirrhosis, there is no definite association between HP and gallstones or other causes of biliary obstruction ${ }^{[12-14]}$. Moreover, HP has not been shown to cause biliary obstruction in the absence of an ulcer.

Our patient developed a severe, obstructive, inflammatory mass in the antrum despite the absence of risk factors for peptic ulcer disease or gastritis such as tobacco abuse, alcoholism, immunodeficiency, or non-steroidal anti-inflammatory drug use. We hypothesize that her Burmese origins predisposed her to a virulent HP strain that produced severe disease. Though unlikely, it is also possible that a peptic ulcer within the mass contributed to gastric outlet obstruction but was missed during the initial EGD.

An ectopic biliary orifice within the duodenal bulb was also diagnosed in this patient after the inflammatory mass healed. It is likely that biliary obstruction and/or stone formation developed as a result of the orifice being located within the area of inflammation. Indeed, this entity is a rare but recognized risk factor for choledocholithiasis and biliary pain ${ }^{[15-17]}$. The ectopic biliary oriface also may have allowed biliary colonization with HP. Bile reflux in these patients has also been known to aggravate gastritis ${ }^{[16]}$.

Finally, the common bile duct stone identified during follow-up ERCP was attributed to bacterial colonization of the biliary tree from the indwelling plastic stent but it is possible that the stone was present earlier and missed during the initial ERCP. Given the size of the stone, we feel this is unlikely. But if so, the stone could have produced or exacerbated her presenting symptoms early on.

To our knowledge, this is the first description of HP causing gastric and biliary obstruction concurrently. Clinicians should be wary of such benign entities when approaching a patient with jaundice and a gastric mass, even when initial studies point to cancer. As this case shows, such a patient may be treated conservatively with endoscopic and medical therapy and thereby avoid a surgical resection. Certainly, the prognosis is favorable for such a patient, and unnecessary anxiety and complications can be minimized.

\section{Author contributions}

Dr. Augustin Attwell served as the patient's gastroenterologist throughout the treatment period described. He drafted, edited, and submitted the manuscript text and edited the final images. 
Dr. Jeffrey Duman served as the patient's consulting Gastroenterology fellow during the patient's hospitalization. He selected, edited, and downloaded the radiologic and endoscopic images for the manuscript.

Dr. Maxwell Smith selected, photographed, and edited the histology images for this manuscript. He also drafted the associated figure legends.

\section{Conflict of interests}

We have no conflicts of interest to disclose, and there was no financial incentive, reimbursement, or other support for this manuscript.

\section{References}

[1] Suerbaum S, Michetti P. Helicobacter pylori injection. N Engl J Med. 2002; 347: 1175-86. PMid: 12374879. http://dx.doi.org/10.1056/NEJMra020542

[2] Gisbert JP, Pajares JM. Review article: Helicobacter pylori infection and gastric outlet obstruction - prevalence of the infection and role of antimicrobial therapy. Aliment Pharmacol Ther. 2002; 16: 1203-8. http://dx.doi.org/10.1046/j.1365-2036.2002.01275.x

[3] De Boer WA, Driessen WM. Resolution of gastric outlet obstruction after eradication of Helicobacter pylori. J Clin Gastroenterol. 1995; 21: 329-30. http://dx.doi.org/10.1097/00004836-199512000-00019

[4] De Boer WA. Gastric outlet obstruction and Helicobacter pylori. Am J Gastroenterology. 1997; 92: 362-3. PMid: 9040231.

[5] Annibale B, Marignani M, Luzzi I, Delle Fave GF. Peptic ulcer and duodenal stenosis: role of Helicobacter pylori infection. Ital J Gastroenterol. 1995; 27: 26-8. PMid: 7795284.

[6] Taskin V, Gurer I, Ozyilkan E, Sare M, Hilmioglu F. Effect of Helicobacter pylori eradication on peptic ulcer disease complicated with outlet obstruction. Helicobacter. 2000; 5: 38-40. PMid: 10672050. http://dx.doi.org/10.1046/j.1523-5378.2000.00005.x

[7] Lam Y, Lau JY, Law KB, Sung JJ, Chung SS. Endoscopic balloon dilation and Helicobacter pylori eradication in the treatment of gastric outlet obstruction. Gastrointest Endosc. 1997; 46: 379-80. http://dx.doi.org/10.1016/S0016-5107(97)70134-2

[8] Yusuf TE, Brugge WR. Endoscopic therapy of benign pyloric stenosis and gastric outlet obstruction. Curr Opin Gastroenterol. 2005; 22: 570-3. PMid: 16891891. http://dx.doi.org/10.1097/01.mog.0000239874.13867.41

[9] Fuller JW. Common bile duct obstruction secondary to peptic ulcer. Am Surg. 1975; 41: 640-2. PMid: 1163906.

[10] Isaeva GS, Abuzarova ER, Valeeva LV, et al. Helicobacter pylori in patients with disorders of the hepatobiliary system. Zh Mikrobiol Epidemiol Immobiol. 2009; 2: 96-101. PMid: 19459487.

[11] Apostolov E, Al-Soud WA, Nilsson I, et al. Helicobacter pylori and other Helicobacter species in gallbladder and liver of patients with chronic cholecystitis detected by immunological and molecular methods. Scand J Gastroenterol. 2005; 40: 96-102. PMid: 15841721. http://dx.doi.org/10.1080/00365520410009546

[12] Leong RWL, Sung JJY. Review article: Helicobacter species and hepatobiliary diseases. Aliment Pharmacol Ther. 2002; 16: 1037-45. http://dx.doi.org/10.1046/j.1365-2036.2002.01282.x

[13] Wadstrom T, Ljungh A. Primary biliary cirrhosis and primary sclerosing cholangitis are of infectious origin! Gut. 2001; 49: 454-458. PMid: 11550663.

[14] Durazzo M, Rosina F, Premoli A, et al. Lack of association between seroprevalence of Helicobacter pylori infection and primary biliary cirrhosis. World J Gastroenterol. 2004; 10: 3179-81. PMid: 15457568.

[15] Sezgin O, Altintas E, Ucbilek E. Ectopic opening of the common bile duct into various sites of the upper digestive tract: a case series. Gastrointest Endosc. 2010; 72: 198-203. PMid: 20493479. http://dx.doi.org/10.1016/j.gie.2010.02.012

[16] Lee SS, Kim MH, Lee SK, Kim KP, Kim HJ, Bae JS, et al. Ectopic opening of the common bile duct in the duodenal bulb: clinical implications. Gastrointest Endosc. 2003; 57: 679-82. PMid: 12709696. http://dx.doi.org/10.1067/mge.2003.210

[17] Song HS, Jun DW, Kim SH, et al. Recurrent duodenal ulcer and cholangitis with ectopic opening of the bile duct in the duodenal bulb. Gastrointest Endosc. 2007; 65: 324-5. PMid: 17258995. http://dx.doi.org/10.1016/j.gie.2006.06.023 